\title{
Comparative efficacious study between preoperative pregabalin and gabapentin on postoperative pain in abdominal hysterectomy: an institutional experience
}

\author{
Gayathri K. B. ${ }^{1 *}$, Prem Swaroop V. ${ }^{2}$, Sajana G. ${ }^{1}$, Uday ${ }^{2}$, Bhargav P. R. K. ${ }^{3}$
}

\author{
${ }^{1}$ Department of Obstetrics and Gynecology, ${ }^{2}$ Department of Anaesthesiology, Pinnamaneni Siddartha Institute of \\ Medical Sciences, Vijayawada, Andhra Pradesh, India \\ ${ }^{3}$ Department of Endocrine Surgery, Endocare Hospital, Vijayawada, Andhra Pradesh, India
}

Received: 17 September 2017

Accepted: 26 October 2017

\section{*Correspondence: \\ Dr. Gayathri K. B., \\ E-mail: endoanswers@gmail.com}

Copyright: (c) the author(s), publisher and licensee Medip Academy. This is an open-access article distributed under the terms of the Creative Commons Attribution Non-Commercial License, which permits unrestricted non-commercial use, distribution, and reproduction in any medium, provided the original work is properly cited.

\begin{abstract}
Background: Pain is a consistent and predominant complaint following surgical intervention including abdominal open hysterectomy. A multimodal approach has been suggested to improve postoperative analgesia and to reduce opioid related side effects. In this context we conducted a comparative study on efficacy between gabapentin and pregabalin on postoperative pain relief.

Methods: In this prospective randomised study, 60 patients were divided in to two arms group G and group P. 900 $\mathrm{mg}$ of gabapentin and $300 \mathrm{mg}$ of pregabalin were administered orally one hour before spinal anaesthesia to respective groups. Hemodynamic parameters such as heart rate, mean arterial pressure, respiratory rate was monitored pre, per and postoperatively. Also, the need for first analgesic dose and visual analog pain score were documented in all subjects of both groups. Statistical analysis with SPSS 16.0 performed.

Results: There was significant fall in mean arterial pressure in group $G$ than group P patients. Further the fall in mean pulse rate was more in group $\mathrm{G}$ compared to group $\mathrm{P}$ throughout pre, per and post-operative phases. In terms of mean postoperative time required for first dose of analgesic drug, pregabalin and gabapentin was required after 7 and 5 hours respectively. There was a statistically significant change in Visual Analogue Scale, showing pregabalin as better drug than gabapentin in post operative pain control with score 5 and 7 respectively.

Conclusions: Pre-emptive analgesia with pregabalin appears to be superior to gabapentin as a part of multimodal perioperative pain management in abdominal hysterectomy.
\end{abstract}

Keywords: Gabapentin, Hysterectomy, NSAIDS, Opioids, Pain, Pregabalin

\section{INTRODUCTION}

Pain is a consistent and predominant complaint following any surgical intervention. Adequate pain relief is considered a basic human right. Failure to relieve pain is morally and ethically unacceptable. High-quality pain control after surgery is still a major challenge. Opioids, NSAIDS have been the mainstay of postoperative pain management, they are not free from side effects. Surgical stimulation is associated with central and peripheral sensitization. Antihyperalgesic drugs improve postoperative pain by preventing the development of central sensitization. ${ }^{1}$ Prevention and treatment of postoperative pain plays an important role in the early mobilization and well being of the surgical patient. A multimodal and novel pain research approaches have been suggested to improve postoperative analgesia and to reduce opioid related side effects. In this context, we set 
out to compare the efficacy of pregabalin vs gabapentin for postoperative analgesia after abdominal hysterectomy.

Aims and objectives of present study were Comparative study of premedication effect of oral pregabalin versus gabapentin on post-operative pain in abdominal hysterectomies, to compare the efficacy of pregabalin and gabapentin in quality and duration on post-operative acute pain relief, to analyse and compare the effect of the drugs on vital parameters, to study the post-operative requirement of analgesics and to compare the side effects of pregabalin and gabapentin.

\section{METHODS}

\section{Inclusion criteria}

- Patients scheduled for elective gynecological abdominal hysterectomy procedure above 35 years 60 years

- Procedure done under spinal anesthesia

- Patients of American Society of Anesthesiologists (ASA) grade I or II.

\section{Exclusion criteria}

- Patients with contraindications to spinal anesthesia

- Patients with major neurological, cardiovascular, metabolic, respiratory, renal disease or coagulation abnormalities were excluded.

- Emergency surgeries.

- Patient having severe dizziness with Gabapentin and Pregabalin.

In this Prospective randomised comparative study, sixty patients scheduled for infraumbilical hysterectomy ranging from 20-70 years of age with ASA grade I and II were selected. After getting ethical clearance, informed consent and preanesthetic assessment of the selected patients for the study were done. Patients were randomly allocated to one of the two group of thirty by hidden named slip in a box method. Patients allocated to Group G (900 mg gabapentin), Group P (pregabalin $300 \mathrm{mg}$ ). On the day of surgery, vital parameters and electrocardiography [ECG] of all the patients were recorded in preanestheic room and then the drug selected for the study was given with a sip of water in the morning, 60 minutes before administering spinal anaesthesia.

On entering into the OT, intravenous (IV) line was secured by using 18 Gauge cannula and preoperative vitals (pulse, $\mathrm{BP}$, respiratory rate, $\mathrm{SpO}_{2}$ ) were recorded. Preloading ringer lactate at the rate of $15 \mathrm{ml} / \mathrm{kg} / \mathrm{h}$. Spinal anesthesia was instituted at L3-L4 interspace and a volume of $3.5 \mathrm{ml}$ of $0.5 \%$ bupivacaine heavy injected over $30 \mathrm{~s}$ through a 26 Gauge spinal needle. Patient was placed in the supine position with a $15^{\circ}$ head down tilt to achieve the level of block of T10). Fluid administration was continued intraoperatively and hypotension, if any was treated with fluid replacement. Motor block was recorded according to the Bromage scale. ${ }^{2}$

Intraoperative vital parameters were recorded. Fluid administration was continued intra-operatively and a decrease in mean arterial pressure greater than $15 \%$ below the pre-anesthetic baseline value was treated with incremental doses of injection Mephenteremine $6 \mathrm{mg} \mathrm{IV}$. A decrease in heart rate below 50 beats/min was treated with incremental doses of atropine $0.3 \mathrm{mg} \mathrm{IV}$.

Pain was assessed postoperatively by visual analogue scale (VAS) immediate postoperatively and every two hourly thereafter, patient with VAS score of more than three were administered diclofenac $1 \mathrm{mgkg}^{-1}$ intramuscularly. Time since spinal anaesthesia to first dose of analgesic and total dose of analgesic in first 24 hours was recorded. Patient was kept under observation for a total period of $24 \mathrm{~h}$ to observe for the total number of doses of analgesic required and any side-effects.

Any complications like dizziness, somnolence, diplopia, vomiting, confusion, pain, and urinary retention were recorded in first 24 hours post- operative period. Results of both the drugs were analysed and compared.

\section{Statistical analysis}

Statistical analysis was performed with the SPSS, version 15.0 for Windows Statistical Software Package (SPSS Inc., Chicago, IL, USA). Categorical data, i.e., ASA grade, type of surgery and the incidence of adverse events (hypotension, bradycardia, respiratory depression, nausea and vomiting) were presented as numbers and proportion of these data were compared in two groups and the difference in proportion was inferred by Chi-square test. Demographic data (age, weight), duration of surgery, VAS score, total duration of analgesia and requirement of rescue analgesia were expressed as mean \pm standard deviation and these data were compared in all three groups and difference in means were inferred by analysis of variance (ANOVA)-test of significance. For significance $\mathrm{P}$ value $\leq 0.05$ was considered as significant for both types of data.

\section{RESULTS}

Sixty patients, thirty in each group, were included in the study and analyzed. The groups were comparable with respect to demographic characteristics like age, weight, physical status and duration of surgery. The intraoperative hemodynamic values i.e, Mean Blood Pressure, Pulse rate and Respiratory rate were monitored.

As shown in Table 1, ASA grades were comparable between both groups, with most of patients falling in grade 1 ASA with 4:1 ratio. The mean age of both groups was $40.1 \pm 7.2(32-59)$ in group $G$ and $42 \pm 6.4$ (29-62) were comparable authenticated by statistical significance of $\mathrm{P}$ value $=0.22$. 
Table 1: ASA distribution between both groups.

\begin{tabular}{|l|llll|}
\hline & ASA & & & \\
\hline & 1 & & $\mathbf{2}$ & \\
\hline Group & Count & \% & Count & \% \\
\hline Gabapentin 900mg & 23 & 76.7 & 7 & 23.3 \\
\hline Pregabalin 300mg & 24 & 80.0 & 6 & 20.0 \\
\hline
\end{tabular}

As depicted in Figure 1, compared to pre operative, Intra operative, post operative blood pressure, there was significant fall in mean arterial pressure in group $G$ than group $\mathrm{P}$ patients.

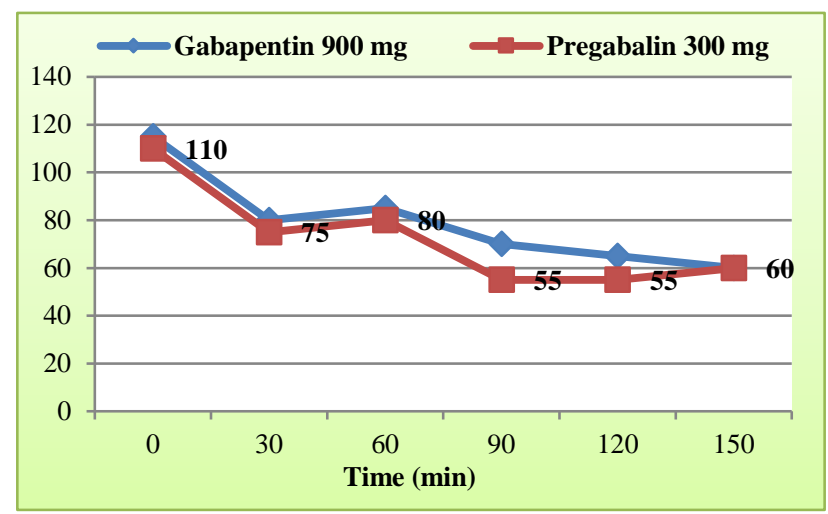

Figure 1: Comparison of mean arterial pressure in both groups.

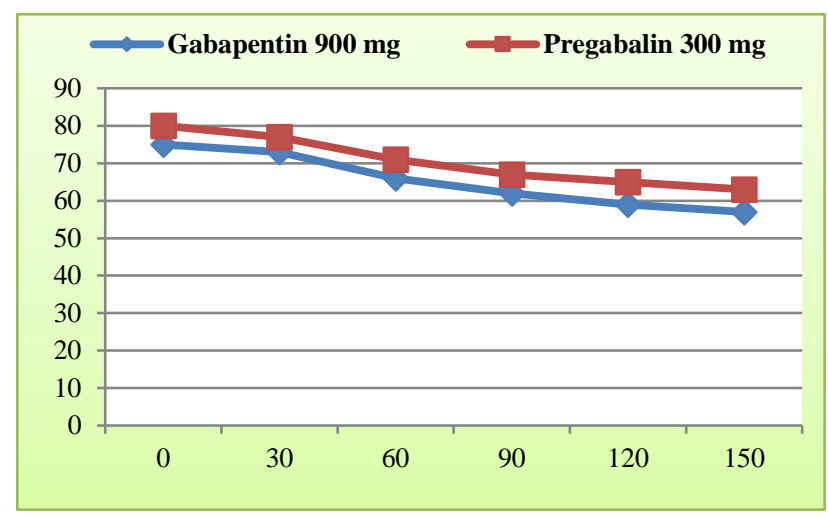

Figure 2: Comparison of mean pulse pressure between the study groups.
In Figure 2, the fall in mean pulse rate, which was more in group $\mathrm{G}$ compared to group $\mathrm{P}$ throughout pre, per and post-operative phases is shown in detail.

As detailed in Table 2, the fall in mean respiratory rate was more in group $G$ than group $P$ in post operative period. Table 3 shows the postoperative time required for first dose of analgesia between both groups. In terms of mean postoperative time required for first dose of analgesic drug, Pregabalin and gabapentin was required after 7 and 5 hours respectively.

As detailed in Table 4, there was a statistically significant change in Visual Analogue Scale, showing Pregabalin as better drug than Gabapentin in post operative pain Control with score 5 and 7 respectively.

Table 2: Comparison of mean respiratory rate between both study groups.

\begin{tabular}{|c|c|c|c|c|c|}
\hline \multirow{2}{*}{$\begin{array}{l}\text { Respirator } \\
\text { y rate }\end{array}$} & \multicolumn{2}{|c|}{$\begin{array}{l}\text { Gabapentin } \\
900 \mathrm{mg}\end{array}$} & \multicolumn{2}{|c|}{$\begin{array}{l}\text { Pregabalin } \\
300 \mathrm{mg}\end{array}$} & \multirow{2}{*}{$\begin{array}{l}\text { P- } \\
\text { value }\end{array}$} \\
\hline & Mean & SD & Mean & SD & \\
\hline At $0 \mathrm{~min}$ & 18 & 2 & 17 & 3 & \\
\hline At $1 \mathrm{~min}$ & 17 & 2 & 16 & 3 & 0.04 \\
\hline At $3 \mathrm{~min}$ & 15 & 2 & 15 & 2 & 0.06 \\
\hline At $5 \mathrm{~min}$ & 14 & 2 & 15 & 2 & 0.02 \\
\hline At $10 \mathrm{~min}$ & 14 & 2 & 15 & 2 & 0.42 \\
\hline At $20 \mathrm{~min}$ & 14 & 2 & 15 & 2 & 0.42 \\
\hline At $30 \mathrm{~min}$ & 13 & 2 & 15 & 3 & 0.05 \\
\hline At $45 \mathrm{~min}$ & 13 & 2 & 15 & 2 & 0.33 \\
\hline At $60 \mathrm{~min}$ & 13 & 2 & 15 & 2 & 0.16 \\
\hline At $120 \mathrm{~min}$ & 13 & 1 & 15 & 2 & 0.05 \\
\hline At $180 \mathrm{~min}$ & 13 & 2 & 15 & 2 & 0.6 \\
\hline
\end{tabular}

Table 3: First analgesic dose required in hours.

\begin{tabular}{|llllll|}
\multirow{2}{*}{ Parameter } & \multicolumn{2}{l}{$\begin{array}{l}\text { Gabapentin } \\
\text { 900mg }\end{array}$} & \multicolumn{2}{l}{$\begin{array}{l}\text { Pregabalin } \\
300 \mathrm{mg}\end{array}$} & \multicolumn{2}{c}{ P-value } \\
\cline { 2 - 5 } & Mean & SD & Mean & SD & \\
\hline Hours & 5 & 1 & 7 & 1 & $<0.01$ \\
\hline
\end{tabular}

None of the patients in either groups experienced complications such as nausea, vomiting, dizziness, dry mouth, confusion, anxiety, back pain or blurred vision.

Table 4: Comparison of VAS between patients of both the groups.

\begin{tabular}{|c|c|c|c|c|c|c|c|c|}
\hline \multirow{2}{*}{ Time } & \multicolumn{3}{|c|}{ Gabapentin 900mg } & \multicolumn{3}{|c|}{ Pregabalin 300mg } & \multirow{2}{*}{$\begin{array}{l}\text { Comparison } \\
\text { (G vs P) }\end{array}$} & \multirow{2}{*}{ P-value } \\
\hline & Median & Mean VAS & SD & Median & Mean VAS & SD & & \\
\hline $0 \mathrm{~min}$ & 4 & 4 & 1 & 2 & 2 & 1 & - & - \\
\hline $1 \mathrm{Hr}$ & 4 & 4 & 2 & 3 & 3 & 1 & $0 \mathrm{~min}$ to $1 \mathrm{Hr}$ & 0.10 \\
\hline $2 \mathrm{Hr}$ & 5 & 5 & 2 & 3 & 3 & 1 & $1 \mathrm{Hr}$ to $2 \mathrm{Hr}$ & 0.04 \\
\hline $3 \mathrm{Hr}$ & 5 & 5 & 2 & 3 & 3 & 1 & $2 \mathrm{Hr}$ to $3 \mathrm{Hr}$ & 0.89 \\
\hline $4 \mathrm{Hr}$ & 6 & 6 & 2 & 4 & 3 & 2 & $3 \mathrm{Hr}$ to $4 \mathrm{Hr}$ & 0.11 \\
\hline $12 \mathrm{Hr}$ & 7 & 7 & 1 & 5 & 5 & 2 & $4 \mathrm{Hr}$ to $12 \mathrm{Hr}$ & $<0.01$ \\
\hline$P$ value $(0 m-12 \mathrm{Hr})$ & $<0.01$ & & & $<0.01$ & & & - & - \\
\hline
\end{tabular}




\section{DISCUSSION}

Pain is the predominant complaint in postoperative period. High-quality pain control after surgery is still a major challenge. Pain is one of the cause for delayed discharge. The management of postoperative pain has received much interest in recent years. The degree of postoperative pain, as ultimately perceived by the patient, is multifactorial and depends on variables such as type and duration of the operation, type of anaesthesia and analgesia used, and the patient's mental and emotional state. ${ }^{1}$ Of the many methods of postoperative pain relief, the oldest and most widely used is parenteral opioids. ${ }^{3}$

The classic pain pathway was once described as a neuronal signaling pathway that commenced in the periphery following an injury or a noxious event and was then transduced via nociceptive receptors (nociceptors) and transmitted along the primary afferents to the spinal cord then upwards to the brain. The electrical signal (i.e. action potentials) transmitted the location and the intensity of the noxious stimulus via the spinal cord to the brain. ${ }^{4}$ After surgical incision, inflammatory mediators released by damaged tissue trigger an inflammatory cascade. This inflammatory response reduces the threshold and increases the responsiveness of nociceptors (sensory receptors on $\mathrm{C}$-fibers and $\mathrm{A} \delta$ fibres) to subsequent input in the damaged tissue; a phenomenon known as peripheral sensitization. ${ }^{5,6}$

The body's neurophysiological responses to any insult, including surgery, may initially serve a protective function (i.e. pain limits further use) and promote healing. Features of central sensitization include an increased responsiveness to activation, reduced threshold, expanded receptive fields, and spontaneous activity following injury, all of which contribute to increased pain after surgery. ${ }^{7}$ Post-surgical pain arises from predominantly two distinct processes: nociception, and inflammation which is a consequence of trauma to peripheral tissues. ${ }^{8}$

Gabapentin and Pregabalin have been used in treatment of neuropathic pain as well as postoperative pain with gratifying results. However, there is paucity of studies for comparison with each other. This study was designed to compare their efficacy with respect to increase in duration of analgesia, reduction in total post -operative requirements of analgesics and side effects. With this background in mind, we designed this study to test the hypothesis that the preoperative use of pregabalin will reduce the consumption of analgesics after abdominal hysterectomy and to compare its efficacy and side effects with that of gabapentin.

Another objective was to determine their effects on postoperative pain scores and side effects using regular analgesics, sedatives and anticonvulsants. This study assesses their efficacy in prolonging the analgesic effect of spinal anesthesia and post-operative analgesic requirement in patients undergoing total abdominal hysterectomy.

With the advances in the understanding of the pathophysiology of pain, multimodal analgesia has become the standard of practice to treat moderate to severe postsurgical pain following orthopedic surgery. ${ }^{9}$ This practice involves the use of different classes of analgesic agents with different routes of administration to:

- provide superior pain relief at rest and with movement,

- reduce opioid consumption, and

- reduce analgesic-relate adverse effects

Gabapentin $\left(\mathrm{C}_{9} \mathrm{H}_{17} \mathrm{NO}_{2}\right)$ and Pregabalin $\left(\mathrm{C}_{8} \mathrm{H}_{17} \mathrm{NO}_{2}\right)$ are GABAergic anticonvulsant and depressant of central nervous system. Gabapentin and pregabalin binds with high affinity to $\alpha_{2} \delta$ subunit containing voltage gated calcium channel (VDCC). They increase extracellular GABA concentration in the brain by producing a dose dependent increase in L-Glutamic acid decarboxylase, the enzyme responsible for making GABA result in a decreased release of synaptic neurotransmitters (e.g., glutamate, norepinephrine, GABA, substance P). Gabapentinoids act as membrane stabilizers. ${ }^{10-12}$ Neurophysiological findings indicate that gabapentin also interacts with NMDA receptors, protein kinase $\mathrm{C}$, and inflammatory cytokines. ${ }^{13}$ Pregabalin also increases the density of transporter proteins and increases the rate of functional GABA transport. ${ }^{14}$

These drugs are only available for oral administration and the absorption of gabapentin is slow and limited by active transport in the gastrointestinal tract. ${ }^{15,16}$ Plasma concentrations of gabapentin do not increase proportionally with increasing dose (non-linear absorption). In contrast, pregabalin absorption is more rapid and without a ceiling of amount absorbed.

According to a first order kinetic, pregabalin absorption increases proportionally with increasing dose (linear absorption. ${ }^{17}$ In healthy volunteers peak plasma concentrations are achieved within one hour after the administration of pregabalin, whereas maximum plasma concentrations for gabapentin are attained after 3-4 hours. ${ }^{10,17}$

The bioavailability of pregabalin is high and exceeds 90 percent irrespective of the dosage, whereas the bioavailability of gabapentin drops from 60 percent to 33 percent as the dosage increases from $900 \mathrm{mg}$ to $3600 \mathrm{mg}$ daily (149). Pregabalin has a favourable pharmacokinetic profile compared with gabapentin. ${ }^{10,17}$ When studied in non-humans pregabalin appears to be 3 to 10 times more potent as an anticonvulsant than gabapentin. ${ }^{18,19}$ Pregabalin is 2 to 4 times more potent as an analgesic than gabapentin. ${ }^{18,19}$ 
Pregabalin is 6 times more potent than gabapentin in binding affinity. ${ }^{20} \mathrm{We}$ choose $900 \mathrm{mg}$ of gabapentin to $300 \mathrm{mg}$ of pregabalin. The absorption of gabapentin decreases steadily with increased dose. So, there would be only $35-40 \%$ absorption with $900 \mathrm{mg}$ amounting to $315-360 \mathrm{mg}$ of active drug, whereas $300 \mathrm{mg}$ of pregabalin has $90 \%$ bioavailability which would have a plasma concentration of $270 \mathrm{mg}$ which both are comparable. Though peak plasma concentration reached by Gabapentin is delayed but the time from the drug administration to starting of surgery there was a time lag of 2-3 hrs which gave sufficient time for peak effect of both the drugs.

Present study showed that $300 \mathrm{mg}$ pregabalin is more effective drug for premedication to reduce pain score than gabapentin $900 \mathrm{mg}$ as it did not cause much fall in mean arterial pressure and pulse rate compared to gabapentin, time to first request of analgesics was longer in pregabalin group (7hr) compared to Gabapentin (5 hrs). Better VAS scores were seen with pregabalin (mean 3-5) compared to Gabapentin (mean 5-7). Similar results have been observed by Ghai A study. ${ }^{21}$ Oral pregabalin and Gabapentin are useful adjuvants for the management of post operative pain by providing analgesia through a different mechanism than opioids making addition of multimodal therapy if not as sole analgesic and higher patient satisfaction. The apparent strength of this study is $300 \mathrm{mg}$ of pregabalin is selected compared to lower doses as low dosage does not produce an effective pain relief as observed by Peach et al. ${ }^{22}$

\section{CONCLUSION}

Pre-emptive analgesia with pregabalin appears to be superior in safety, analgesic requirement and patient satisfaction to gabapentin as a part of multimodal perioperative pain management in abdominal hysterectomy.

\section{Funding: No funding sources}

Conflict of interest: None declared

Ethical approval: The study was approved by the Institutional Ethics Committee

\section{REFERENCES}

1. James D, Justins D. Acute post-operative pain. In: Healy TE, Knight PR, eds. Wylie and Churchill Davidson's A practice of Anaesthesia. $7^{\text {th }}$ ed. London: Arnold Publishers; 2003: 1213-34.

2. Turan A, Karamanlioglu B, Memis D, Hamamcioglu MK, Tükenmez B, Pamukçu Z et al. Analgesic effects of gabapentin after spinal surgery. Anesthesiology. 2004;100:935-8.

3. Woolf CJ, Chong MS. Preemptive analgesiaTreating postoperative pain by preventing the establishment of central sensitization. Anesth Analg. $1993 ; 77: 362-79$.
4. Woolf CJ, Salter MW. Neuronal plasticity: increasing the gain in pain. Science. 2000;288:176569.

5. Costigan M, Scholz J, Woolf CJ. Neuropathic pain: a maladaptive response of the nervous system to damage. Annu Rev Neurosci. 2009;32:1-32.

6. Fitzgerald M. The development of nociceptive circuits. Nat Rev Neurosci. 2005;6:507-20.

7. Latremoliere A, Woolf CJ. Central sensitization: a generator of pain hypersensitivity by central neural plasticity. J Pain. 2009;10: 895-926.

8. Woolf CJ, Ma Q. Nociceptors--noxious stimulus detectors. Neuron. 2007;55:353-64.

9. Joshi GP. Multimodal analgesia techniques and postoperative rehabilitation. Anesthesiol Clin North America. 2005;23:185-202.

10. Taylor CP. Mechanisms of analgesia by gabapentin and pregabalin- calcium channel alpha2-delta [Cavalpha2-delta] ligands. Pain. 2009;142:13-16.

11. Field MJ, Cox PJ, Stott E, Melrose H, Offord J, Su $\mathrm{TZ}$ etal. Identification of the alpha2-delta-1 subunit of voltage-dependent calcium channels as a molecular target for pain mediating the analgesic actions of pregabalin. Proceedings of the National Academy of Sciences of the U.S.A. 2006;103:1753742.

12. Taylor CP, Angelotti T, Fauman E. Pharmacology and mechanism of action of pregabalin: The calcium channel alpha(2)-delta (alpha(2)-delta) subunit as a target for antiepileptic drug discovery. Epilepsy Res. 2007;73:137-50.

13. Sze PY. L-Glutamate decarboxylase. Adv Experiment Med Biol. 1979;123:59-78.

14. Ankesh K, Bali A. Implications and mechanism of action of gabapentin in neuropathic pain. Arch Pharmacal Res. 2013;36:237-251.

15. Stewart BH, Kugler AR, Thompson PR, Bockbrader HN. A saturable transport mechanism in the intestinal absorption of gabapentin is the underlying cause of the lack of proportionality between increasing dose and drug levels in plasma. Pharmaceut Res. 1993;10:276-81.

16. Bockbrader HN, Wesche D, Miller R, Chapel S, Janiczek N, Burger P. A comparison of the pharmacokinetics and pharmacodynamics of pregabalin and gabapentin. Clin Pharmacokinetics. 2010;49:661-9.

17. Bryans, Justin S, Wustrow, David J. 3-Substituted GABA analogs with central nervous system activity: A review". Med Res Rev. 1999;19:149-77.

18. Lauria-Horner BA, Pohl RB. Pregabalin: a new anxiolytic. Expert Opinion on Investigational Drugs. 2003;12:663-72.

19. O'Brien C. Drug addiction and drug abuse. In: Brunton LB, Lazo JS, Parker KL, eds. Goodman and Gilman's The Pharmacological Basis of Therapeutics. $11^{\text {th }}$ ed. New York, NY: McGraw-Hill; 2005:607-629. 
20. McMahon, Stephen B. Wall and Melzack's textbook of pain. $6^{\text {th }}$ ed. Philadelphia, PA: Elsevier/Saunders; 2013:515.

21. Ghai A, Gupta M, Hooda S, Singla D, Wadhera R. A randomized controlled trial to compare pregabalin with gabapentin for postoperative pain in abdominal hysterectomy. Saudi J Anaesthesia. 2011 Jul;5(3):252-7.

22. Paech MJ, Gay R, Chua S, Scott K, Christmas T, Doherty DA. A randomized, placebo-controlled trial of preoperative pregabalin for postoperative pain relief after minor gynaecological surgery. Anesth Analg. 2007;105:1449-53.

Cite this article as: Gayathri KB, Swaroop PV, Sajana G, Uday, Bhargav PRK. Comparative efficacious study between preoperative pregabalin and gabapentin on postoperative pain in abdominal hysterectomy: an institutional experience. Int J Reprod Contracept Obstet Gynecol 2017;6:5373-8. 